\title{
Atropine Prevents Increases in Brain Blood Flow during Hypertension in Newborn Piglets
}

\author{
ANN-MARI BRUBAKK, DAG BRATLID, WILLIAM OH, ALICE C. YAO, AND \\ BARBARA S. STONESTREET \\ Department of Pediatrics, Women and Infants Hospital of Rhode Island, Section of Pediatrics, and Brown \\ University Program in Medicine, Providence, Rhode Island 02908
}

\begin{abstract}
Cerebral hyperperfusion associated with hypertension, may play an important role in the pathogenesis of intraventricular hemorrhage in preterm infants. To examine the effect of hypertension on changes in total and regional brain blood flow (BBF), we increased the mean arterial blood pressure (MABP) in nine awake newborn piglets by an infusion of $0.7 \mathrm{mg} / \mathrm{kg}$ of metaraminol bitartrate (Aramine) (group I) and studied cerebral circulatory changes. In order to prevent the Aramine-associated bradycardia, we pretreated nine other piglets with atropine, which produced a higher level of hypertension (group II). MABP and BBF were measured and cerebral vascular resistance (CVR) was calculated during baseline, the Aramine infusion, and twice at decreasing MABP following the discontinuation of the Aramine infusion. In group $I$, the significant increase in MABP from $68 \pm 3$ to $100 \pm 3$ $\mathrm{mm} \mathrm{Hg}$ (mean $\pm \mathrm{SEM}$ ) during the Aramine infusion resulted in a significant increase in BBF $(98 \pm 9$ to $118 \pm$ $11 \mathrm{ml} \cdot \mathrm{min}^{-1} \cdot 100 \mathrm{~g}^{-1}$ ). MABP decreased significantly (although remained significantly above baseline levels), when Aramine was discontinued; however, total BBF remained elevated. CVR increased during the Aramine infusion, but decreased significan (versus the Aramine-infused state) in the post-Aramine period. Regional BBF increased significantly to the cerebrum and cerebellar cortex, but remained unchanged to the other regions including the brain stem. In group II, the Aramine infusion resulted in a significantly greater increase in MABP, a sustained increase in vascular resistance, and no increase in total BBF. Thus, atropine prevents increased BBF during hypertension in the newborn piglet. (Pediatr Res 18:1121-1126, 1984)
\end{abstract}

\section{Abbreviations}

MABP, mean arterial blood pressure

IVH, intraventricular hemorrhage

BBF, brain blood flow

CVR, cerebral vascular resistance

Received December 30, 1983; accepted May 14, 1984

Reprint requests may be addressed to Barbara S. Stonestreet, M.D., Women and Infants Hospital of Rhode Island, 50 Maude Street, Providence, RI 02908.

This work was supported in part by Training Grant 1 T32-HD-07232, National Institute of Child Health and Human Development, Bethesda, MD, and a grantin-aid from The American Heart Association with funds contributed in part by the Rhode Island affiliate. A.-M.B., is supported by Leiden State University, Leiden, The Netherlands. D. B. is a recipient of a Fogarty International Fellowship, Public Health Service, Human Health and Science, Grant 5-505-TW02895-02, International Research and Awards Branch, Fogarty International Center, Building 38A Room 613, 9000 Rockville Pike, Bethesda, MD 20205. A. C. Y. collaborated during a sabbatical leave from Downstate Medical Center, State University of New York, Brooklyn, NY.
Increases in MABP have been considered an important factor in the pathogenesis of IVH in low birth weight infants. Sudden increases in MABP have been shown to produce IVH in newborn dogs (9) and fetal sheep (27), possibly by increasing blood flow to the fragile blood vessels of the germinal matrix. In recent clinical studies, a relationship has been established between IVH and ligation of the ductus arteriosus in preterm infants (2), a procedure that significantly increases the MABP (21). A correlation has also been shown to exist between high MABP during the first days of life in preterm infants and the incidence of IVH (31). Even small increases in MABP may increase the risk of IVH in distressed newborn infants, possibly because of impaired autoregulation reported in these infants (19). Therefore, it appears clinically relevant to examine the changes in total and regional BBF during hypertension in an experimental animal. We induced hypertension pharmacologically in newborn piglets. An additional increment in MABP was obtained by pretreating the animals with a cholinergic blocking agent (atropine). During these experiments, we unexpectedly observed a protective effect of atropine on the BBF during hypertension. Thus, in this article, we describe the changes in total and regional BBF during hypertension and the effects of atropine pretreatment on these circulatory changes.

\section{MATERIALS AND METHODS}

Eighteen piglets with a mean weight of $1.4 \mathrm{~kg}$ (range, 0.9-1.7) were studied on the 2 nd to $3 \mathrm{rd}$ day of life. The piglets remained with the sow until the morning of the study. Catheter placement was performed on an infant radiant warmer under general anesthesia using a mixture of $70 \%$ nitrous oxide and $30 \%$ oxygen administered via a headbox, and local infiltration anesthesia using $1 \%$ xylocaine. A $3 \frac{1}{2}$ French vascular catheter (Argyle, St. Louis, MO) was introduced into the left ventricle via the right brachial artery, for injection of radionuclide-labeled microspheres. Polyvinyl catheters (ID $0.58 \mathrm{~mm}$, OD $0.9 \mathrm{~mm}$, Bolab Inc., Lake Havasu, AZ) were placed in 1) the left brachial artery for withdrawal of reference blood samples, 2) the abdominal aorta via a femoral artery for determination of blood pressure, heart rate, arterial blood gases, and hematocrit values, and 3) the vena cava via a femoral vein, for infusion of drugs.

Following catheter placement, the headbox was removed and the animals were allowed to recover from anesthesia. The awake piglets were placed in a closed cardboard box to ensure a disturbance-free environment, and the distal ends of the catheters were exteriorized through a small opening in the box.

Microspheres ( $15 \pm 5 \mu \mathrm{m}$, New England Nuclear) labeled with ${ }^{51} \mathrm{Cr},{ }^{46} \mathrm{Sc},{ }^{95} \mathrm{Nb},{ }^{113} \mathrm{Sn},{ }^{103} \mathrm{Ru}$, and ${ }^{57} \mathrm{Co}$ were utilized to measure brain blood flow according to the technique of Heymann et al. (13). For each blood flow measurement, approximately $9 \times 10^{5}$ radionuclide-labeled microspheres suspended in a $10 \%$ dextran 
solution were injected over $45 \mathrm{~s}$ into the left ventricle. A reference sample of blood from the axillary artery was collected continuously for 2 min beginning $15 \mathrm{~s}$ prior to the microsphere injection, at a withdrawal rate of $1.03 \mathrm{ml} / \mathrm{min}$ using a constant withdrawal pump (Harvard Apparatus, Millis, MA). Blood loss from sampling was replaced with an equal volume of blood obtained from a donor piglet. Adequate mixing of microspheres in the left ventricle was confirmed by comparing blood flow from the right and left cerebrum $(r=0.99, n=9)$.

Baseline BBF was determined after a $2-\mathrm{h}$ recovery period from surgery. In one group of animals (group I), hypertension was induced with metaraminol bitartrate (Aramine), an adrenergic receptor stimulator. The mean total Aramine dose of $0.7 \mathrm{mg} / \mathrm{kg}$ was divided into a bolus injection and a 2 -min infusion. The bolus injection was adjusted to increase the blood pressure maximally; the 2-min infusion maintained the elevated blood pressure while the BBF was being measured. At the end of this BBF determination, the Aramine infusion was discontinued. During the next half-hour (mean time, $28 \mathrm{~min}$; range, 15-49 $\mathrm{min}$ ), the MABP declined slowly, allowing us to perform two additional $\mathrm{BBF}$ deteminations at MABP lower than those obtained during the Aramine infusion, but still significantly elevated compared to baseline values.

During Aramine administration, reflex bradycardia limited the increase in MABP in group I. In order to achieve a greater increase in MABP, the reflex bradycardia was eliminated in nine piglets (group II) by pretreating them with atropine before the induction of hypertension. The study design was exactly the same as for group I except for the following. After the baseline $\mathrm{BBF}$ determination $0.02 \mathrm{mg} / \mathrm{kg}$ of atropine sulfate was administered intravenously and a second baseline BBF was detemined. Following this second baseline measurement, Aramine was infused at the same dose and rate as in group I. The duration of the post-Aramine study period was similar in both groups (mean, $28 \mathrm{~min}$; range, $21-40$ in group II). In group II, the second postAramine determination was performed in seven of the nine animals.

MABP was monitored continuously during the study using a Hewlett-Packard $1280 \mathrm{~B}$ pressure transducer and recorded on a Hewlett-Packard 7754 A polygraph. The mean, systolic, and diastolic blood pressure, pulse pressure, and heart rate represented the mean of five determinations during each BBF measurement. Total CVR was calculated by dividing MABP by total $\mathrm{BBF}$. After each BBF determination, arterial $\mathrm{PaCO}_{2}, \mathrm{PaO}_{2}, \mathrm{pH}$, and base excess were measured using a Corning 165 blood gas analyzer. Arterial hematocrit was measured using the microhematocrit method.

At the end of the study, the animals were sacrificed with an overdose of sodium thiamylal, the catheter placement was confirmed by autopsy, and the brain was removed and weighed. Fixation of the brain, counting of tissue and reference blood samples, and calculation of blood flow were performed as previously described $(13,18)$. Blood flow to various regions of the brain was examined separately; these were isolated as follows: cerebrum, brain stem (from superior colliculus to the spinal cord), cerebellar cortex, cerebellar medulla, caudate nucleus (floor of the third ventricle), and the boundary zone (periventricular area in the frontoparietal region of the brain). The choroid plexus was removed from the lateral ventricles in eight animals from group I and seven animals from group II.

Each reference blood sample and most of the tissue samples contained at least 400 microspheres (13), except in $15 \%$ of the samples from the germinal matrix area, the boundary zone and the cerebellar medulla, and $90 \%$ of the choroid plexus samples, where less than 400 microspheres/sample were found. The mean number of microspheres was as follows: in the caudate nucleus, $969 \pm 71( \pm$ SEM $)$; the boundary zone, $806 \pm 55$; the cerebellar medulla, $1270 \pm 98$; and the choroid plexus, $204 \pm 16$. The low numbers of radionuclide-labeled microspheres may account for a greater variability in the blood flow determinations to these regions.

Statistical analysis of changes within each group was done by analysis of variance for repeated measurements. If a significant difference was found, Dunnet's multiple range $t$ test was used to compare the means to the baseline values (32). The two study groups were compared by unpaired Student's $t$ test. When the two groups were compared during more than one study period, the value accepted as significant was corrected according to the Bonferroni method (30). All values are expressed as mean \pm one standard error of the mean.

\section{RESULTS}

Table 1 summarizes the arterial blood gas and hematocrit values at each blood flow determination in group I (Aramine) and group II (Aramine with atropine pretreatment) piglets. Pretreatment with atropine did not alter the blood gas and hematocrit values. For unexplained reasons, there were minor but significant differences in arterial blood $\mathrm{pH}$ and base excess at various study periods in both groups as noted in Table 1; however, all values were within the physiologic range and should not affect the main parameters of our study, i.e. hemodynamics and brain blood flow.

Table 2 summarizes the changes in MABP, total and regional $\mathrm{BBF}$, and calculated CVR in group I. MABP increased significantly $(p<0.05)$ from a baseline value of $68 \pm 3 \mathrm{~mm} \mathrm{Hg}$ to a peak value of $100 \pm 3 \mathrm{~mm} \mathrm{Hg}$ during the Aramine infusion. This increase in MABP resulted in a significant $(p<0.05)$ increase in both total BBF and total CVR when compared with the baseline value. In the post-Aramine period, the MABP was still significantly $(p<0.05)$ elevated as compared to the baseline value, although it had decreased significantly $(p<0.05)$ from the maximum value obtained during the Aramine infusion. The $\mathrm{BBF}$ values obtained in the post-Aramine period remained unchanged compared to the values obtained during the Aramine infusion and were significantly $(p<0.05)$ higher than the baseline values. However, CVR returned to baseline levels during the post-Aramine period, decreasing significantly $(p<0.05)$ at the end of the experiment from values obtained during Aramine administration.

Hypertension resulted in regional differences in BBF. Blood flow to the cerebrum increased significantly $(p<0.05)$, whereas the blood flow to the brain stem and cerebellum did not. Similarly, within the cerebellum, blood flow to the cerebellar cortex increased significantly $(p<0.05)$ during hypertension, whereas blood flow to the cerebellar medulla did not. No significant changes were found in blood flow to the boundary zone and the caudate nucleus. Blood flow to the choroid plexus decreased significantly $(p<0.05)$ from $418 \pm 59$ to $188 \pm 56 \mathrm{ml} \cdot \mathrm{min}^{-1}$. $100 \mathrm{~g}^{-1}$ during the Aramine infusion. In the post-Aramine period, the choroid plexus blood flow remained significantly $(p<0.05)$ reduced compared to baseline, but increased significantly compared to values during the Aramine infusion.

Table 3 summarizes the mean arterial blood pressure, total and regional brain blood flow, and calculated CVR in group II piglets. MABP did not change following pretreatment with atropine (baseline, $72 \pm 2 \mathrm{~mm} \mathrm{Hg}$; baseline after atropine, $75 \pm 2$ $\mathrm{mm} \mathrm{Hg}$ ), but increased significantly $(p<0.05)$ to a maximum value of $118 \pm 3 \mathrm{~mm} \mathrm{Hg}$ during Aramine infusion. A significant $(p<0.05)$ decline in MABP was observed during the postAramine period ( $94 \pm 3$ and $85 \pm 3 \mathrm{~mm} \mathrm{Hg}$ ); however, these values remained significantly $(p<0.05)$ higher than both baseline values. Total $\mathrm{BBF}$ did not change with atropine pretreatment (baseline, $103 \pm 8$; atropine baseline, $99 \pm 8 \mathrm{ml} \cdot \mathrm{min}^{-1} \cdot 100 \mathrm{~g}^{-1}$ ). During and after the Aramine infusion, total and regional BBF did not differ from baseline values except for the choroid plexus blood flow, where a significant $(p<0.05)$ reduction was noted. CVR remained unchanged after atropine pretreatment, increased 
Table 1. Arterial blood gas and hematocrit values in study subjects*

\begin{tabular}{|c|c|c|c|c|c|}
\hline $\begin{array}{l}\text { Parameter and } \\
\text { group }\end{array}$ & Baseline & $\begin{array}{l}\text { Atropine } \\
\text { baseline }\end{array}$ & Aramine & \multicolumn{2}{|c|}{ Post-Aramine $\dagger$} \\
\hline \multicolumn{6}{|l|}{$\mathrm{pH}$} \\
\hline II & $7.49 \pm 0.01$ & $7.49 \pm 0.01$ & $7.45 \pm 0.01 \ddagger$ & $7.44 \pm 0.01 \ddagger$ & $\begin{array}{c}7.46 \pm 0.02 \\
(7)\end{array}$ \\
\hline \multicolumn{6}{|l|}{$\mathrm{PaCO}_{2}(\mathrm{~mm} \mathrm{Hg})$} \\
\hline \multicolumn{6}{|l|}{$\mathrm{PaO}_{2}(\mathrm{~mm} \mathrm{Hg})$} \\
\hline I & $88.8 \pm 6.5$ & & $85.9 \pm 5.7$ & $86.7 \pm 5.3$ & $79.8 \pm 4.6$ \\
\hline II & $78.2 \pm 4.4$ & $80 \pm 3.1$ & $76.3 \pm 3.1$ & $78.8 \pm 1.8$ & $\begin{array}{c}76.9 \pm 3.9 \\
(7)\end{array}$ \\
\hline \multicolumn{6}{|c|}{ Base excess (mEq/liter) } \\
\hline 1 & $20.9 \pm 1.6$ & & $22.0 \pm 1.9$ & $22.3 \pm 1.7$ & $21.6 \pm 2.1$ \\
\hline II & $21.6 \pm 0.8$ & $20.7 \pm 0.6$ & $22.9 \pm 0.7$ & $23 \pm 1.2$ & $\begin{array}{c}22.7 \pm 1.0 \\
(7)\end{array}$ \\
\hline
\end{tabular}

*Values are means \pm SEM.

$\dagger$ Number of experiments in parentheses, equal to 9 except as indicated. Group I (Aramine); group II (Aramine with atropine pretreatment). $\ddagger p<0.05$ vs. baseline.

$\S p<0.0125 v s$. group II for the same study period.

Table 2. Changes in mean arterial blood pressure and total cerebral vascular resistance $\left(\mathrm{mm} \mathrm{Hg} \cdot \mathrm{ml}^{-1} \cdot 100 \mathrm{~g} \cdot \mathrm{min}\right)$ and regional brain blood flow $\left(\mathrm{ml} \cdot \mathrm{min}^{-1} \cdot 100 \mathrm{~g}^{-1}\right)$ in group I piglets (induction of hypertension with aramine)*

\begin{tabular}{|c|c|c|c|c|}
\hline \multirow[b]{2}{*}{ Parameter $\dagger$} & \multirow[b]{2}{*}{ Baseline } & \multirow[b]{2}{*}{ Aramine } & \multicolumn{2}{|c|}{ Post-Aramine } \\
\hline & & & I & II \\
\hline Mean arterial blood pressure $(\mathrm{mm} \mathrm{Hg})(9)$ & $68 \pm 3$ & $100 \pm 3 \dagger$ & $91 \pm 4 \ddagger \S$ & $83 \pm 2 \ddagger$ \\
\hline Total brain blood flow (9) & $98 \pm 9$ & $118 \pm 11 \ddagger$ & $119 \pm 12 \ddagger$ & $122 \pm 13 \ddagger$ \\
\hline Total cerebral vascular resistance $(9)$ & $0.75 \pm 0.09$ & $0.92 \pm 0.10 \ddagger$ & $0.82 \pm 0.07$ & $0.74 \pm 0.10 \S$ \\
\hline$\dot{Q}$ cerebrum $(9)$ & $97 \pm 9$ & $120 \pm 12 \ddagger$ & $120 \pm 13 \ddagger$ & $123 \pm 14 \ddagger$ \\
\hline$\dot{Q}$ brainstem (9) & $94 \pm 9$ & $103 \pm 8$ & $105 \pm 12$ & $109 \pm 10$ \\
\hline$\dot{Q}$ cerebellum (9) & $103 \pm 10$ & $115 \pm 11$ & $119 \pm 13$ & $126 \pm 14$ \\
\hline$\dot{Q}$ cerebellar cortex $(9)$ & $103 \pm 9$ & $117 \pm 10 \ddagger$ & $123 \pm 13 \ddagger$ & $130 \pm 15 \ddagger$ \\
\hline$\check{Q}$ cerebellar medulla $(9)$ & $103 \pm 15$ & $115 \pm 17$ & $111 \pm 17$ & $117 \pm 18$ \\
\hline$\dot{Q}$ boundary zone $(9)$ & $95 \pm 11$ & $113 \pm 10$ & $109 \pm 12$ & $113 \pm 13$ \\
\hline$\dot{Q}$ caudate nucleus $(9)$ & $126 \pm 10$ & $151 \pm 23$ & $127 \pm 16$ & $132 \pm 15$ \\
\hline$\dot{Q}$ choroid plexus $(8)$ & $418 \pm 59$ & $188 \pm 56 \div$ & $296 \pm 38 \ddagger \S$ & $297 \pm 55 \ddagger \S$ \\
\hline
\end{tabular}

$*$ Values are means \pm SEM. All blood flows $(\dot{Q})$ expressed as $\mathrm{ml} \cdot \mathrm{min}^{-1} \cdot 100 \mathrm{~g}^{-1}$

$\dagger$ Number of experiments in parentheses.

$\ddagger p<0.05$ compared to baseline.

$\S p<0.05$ compared to Aramine.

significantly $(p<0.05)$ during Aramine administration, and remained elevated during the post-Aramine period.

When the data from groups I and II were compared, we observed a distinct difference in the response of BBF and CVR to Aramine-induced hypertension when atropine pretreatment was instituted. As shown in Figure 1, Aramine infusion resulted in a significant increase in MABP from baseline in both groups; the increase was significantly greater in group II (atropine pretreatment) as compared to group I (no atropine) $(p<0.0125)$. During the post-Aramine period, MABP levels were similarly elevated from baseline in both groups. CVR increased significantly $(p<0.05)$ with Aramine administration in both groups; during the post-Aramine period, CVR remained elevated in group II (atropine pretreatment) and decreased significantly ( $p$ $<0.05$ ) from the Aramine-infused state in group I. The significant $(p<0.05)$ and sustained increase in blood flow in group I was not observed in group II, despite the significantly greater increase in MABP during the Aramine infusion in this group. As shown in Figure 2, the blood flow to the cerebrum and cerebellar cortex were significantly $(p<0.05)$ elevated in group I during hypertension but not in group II. The choroid plexus blood flow decreased significantly $(p<0.05)$ during hypertension in both groups.

The changes in heart rate and pulse pressure in the two groups are summarized in Table 4 . The heart rate in group I decreased significantly $(p<0.05)$ during Aramine infusion and the first post-Aramine measurement. During the second post-Aramine measurement, the heart rate had increased significantly $(p<$ 0.05 ) from the value obtained during Aramine infusion but was no longer significantly different from baseline. In group II, heart rate increased significantly $(p<0.05)$ after administration of atropine compared to baseline. Aramine administration resulted 
Table 3. Changes in mean arterial blood pressure, total cerebral vascular resistance ( $\left.\mathrm{mm} \mathrm{Hg} \cdot \mathrm{ml}^{-1} \cdot 100 \mathrm{~g} \cdot \mathrm{min}\right)$, and total and regional brain blood flow $\left(\mathrm{ml} \cdot \mathrm{min}^{-1} \cdot 100 \mathrm{~g}^{-1}\right)$ in group II piglets (atropine pretreatment before induction of hypertension with aramine)*

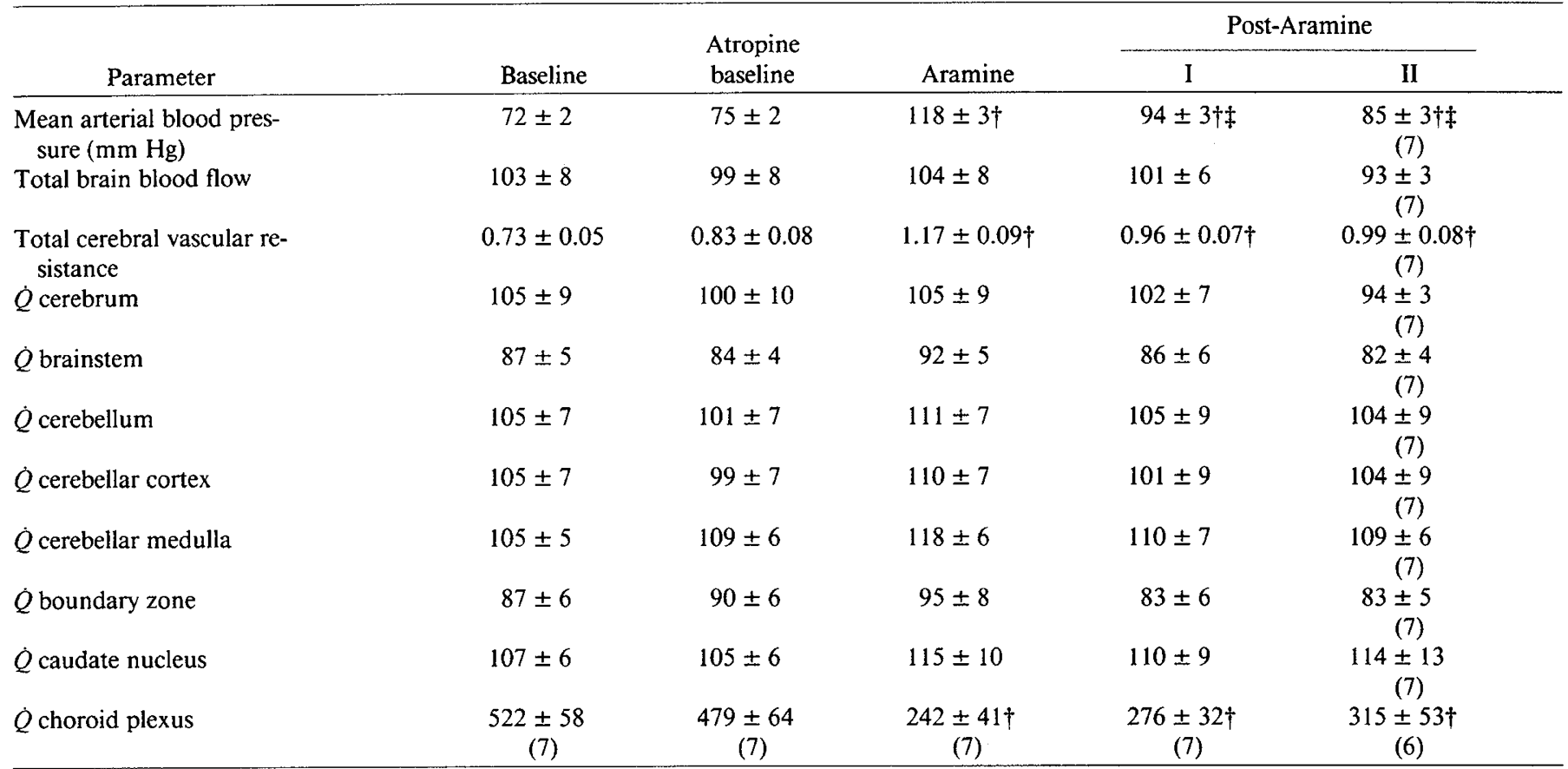

* Values are means \pm SEM. Number of experiments in parentheses, equal to 9 except as indicated. All blood flow $(\dot{Q})$ expressed as $\mathrm{ml}^{-1} \cdot \mathrm{min}^{-1}$. $100 \mathrm{~g}^{-1}$.

$\dagger p<0.05$ compared to baseline.

$\$ p<0.05$ compared to Aramine.

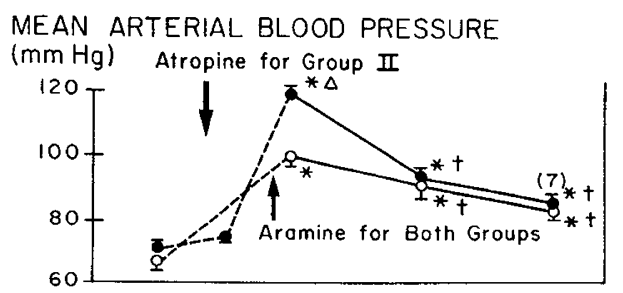

TOTAL CEREBRAL VASCULAR RESISTANCE ( $\mathrm{mm} \mathrm{Hg} \cdot \mathrm{ml}^{-1} \cdot 100 \mathrm{~g} \cdot \mathrm{min}$ )

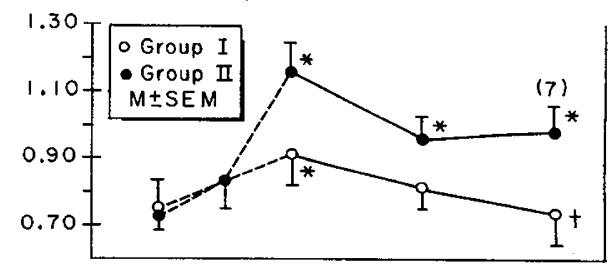

TOTAL BRAIN BLOOD FLOW

$\left(\mathrm{ml} \cdot \mathrm{min}^{-1} \cdot 100 \mathrm{~g}^{-1}\right)$

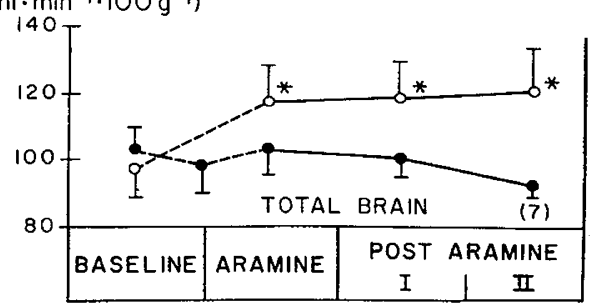

Fig. 1. Mean arterial blood pressure, calculated total cerebral vascular resistance, and total brain blood flow in group I (hypertension induced with Aramine) and group II (atropine pretreatment before induction of hypertension with Aramine). The numbers of determinations are in parentheses. ${ }^{*} p<0.05$ compared to baseline; $\dagger p<0.05$ compared to Aramine; $\Delta p<0.0125$ compared to group II for the same study period.

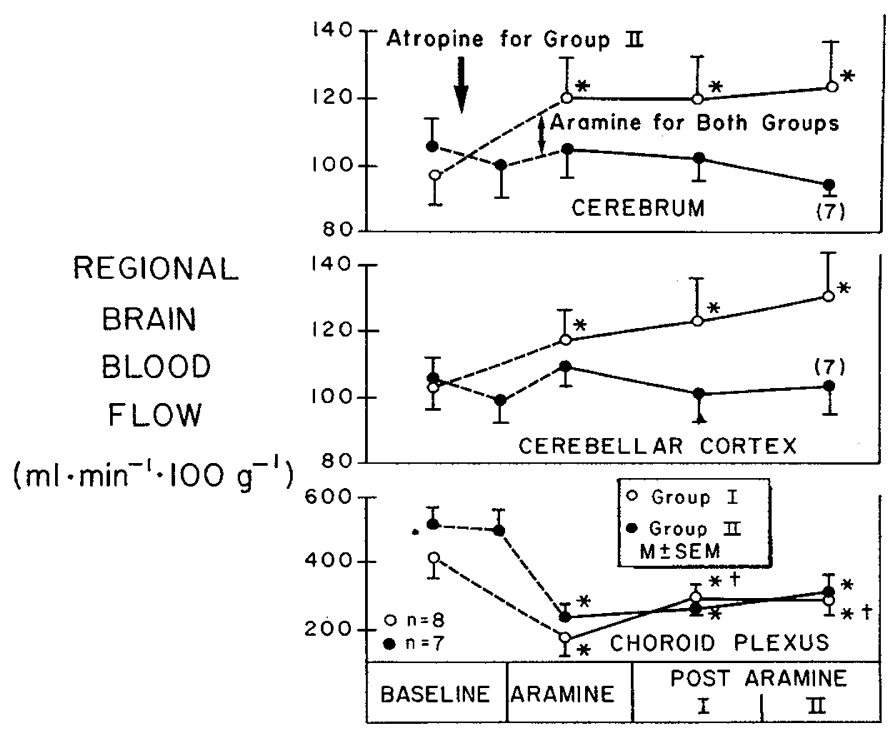

Fig. 2. Total and regional brain blood flow to the cerebrum, cerebellar cortex, and the choroid plexus in group I (hypertension induced with Aramine) and group II (atropine pretreatment before induction of hypertension with Aramine). Number of determinations are in parentheses. $* p<0.05$ compared to baseline; $\uparrow p<0.05$ compared to Aramine; $\Delta p$ $<0.0125$ compared to group II for the same study period.

in a slight decrease in heart rate; however, during the postAramine period, heart rate was again significantly $(p<0.05)$ increased as compared to baseline. During induction of hypertension and the first post-Aramine blood flow determination, the heart rate was significantly higher in group II as compared to group I $(p<0.0125)$. The pulse pressure increased significantly during the Aramine infusion in both groups compared to baseline $(p<0.05)$; in group I, it remained significantly elevated during 
Table 4. Changes in heart rate (beats/min) and pulse pressure ( $\mathrm{mm} \mathrm{Hg}$ ) in the study subjects*

\begin{tabular}{|c|c|c|c|c|c|}
\hline $\begin{array}{l}\text { Parameter and } \\
\text { group }\end{array}$ & Baseline & $\begin{array}{l}\text { Atropine } \\
\text { baseline }\end{array}$ & Aramine & I & II \\
\hline \multicolumn{6}{|l|}{ Heart rate } \\
\hline 1 & $204 \pm 11$ & & $160 \pm 9+t$ & $166 \pm 10 \dagger$ & $187 \pm 12 \S$ \\
\hline \multicolumn{6}{|l|}{ Pulse pressure } \\
\hline I & $44 \pm 4$ & & $64 \pm 6 \dagger$ & $53 \pm 5+\S$ & $44 \pm 4 \S$ \\
\hline
\end{tabular}

\footnotetext{
* Values are means \pm SEM. Number of experiments equal to 9 except those in parentheses.

$\dagger p<0.05$ compared to baseline.

$\ddagger p<0.0125$ versus group II for the same study period.

$\S p<0.05$ compared to Aramine.
}

the first post-Aramine measurement. Compared to the value during the Aramine infusion, the pulse pressure decreased significantly $(p<0.05)$ in the post-Aramine period in both groups. In group II, pulse pressure decreased significantly $(p<0.05)$ at the end of the study compared to the baseline value.

\section{DISCUSSION}

Changes in $\mathrm{BBF}$ during hypertension have not been investigated previously in newborn piglets. In the current report, an acute increase in MABP to a mean of $100 \mathrm{~mm} \mathrm{Hg}$ (group I, in Fig. 1) resulted in a significant and sustained increase in $\mathrm{BBF}$, indicating that the upper limit of the autoregulatory range in newborn piglets is similar to the limit of $90 \mathrm{~mm} \mathrm{Hg}$ found in newborn lambs (26) and dogs (12). When exceeding the autoregulatory range, we would have expected a decrease in CVR as an indication of cerebral vasodilation; instead, we found a significant increase followed by a decrease. Because we did not measure intracranial or cerebral venous pressure simultaneously for the calculation of CVR, a possible explanation is that the CVR is overestimated. Furthermore, the MABP increased more than the CVR (47\% versus $24 \%$ ). Therefore, we speculate that the transient increase in CVR reflects an attempt by the cerebral vasculature to autoregulate in the face of an acute increase in MABP and that attempt failed resulting in an increased BBF. Several investigators $(14,15,20)$ have shown that acute severe arterial hypertension (MABP $170-200 \mathrm{~mm} \mathrm{Hg}$ in the adult cat) results in dilatation of the cerebral arteries and arterioles. This dilatation and the increase in BBF (1) are sustained after normalization of the blood pressure and renders the arteries unresponsive to hypocarbia and other vasoconstrictive agents of the cerebral circulation. Our finding of a sustained increase in BBF, in spite of the post-Aramine decline in arterial blood pressures, suggests that a maximum MABP of not more than $100 \mathrm{~mm} \mathrm{Hg}$ might be sufficient to render the cerebral vasculature unresponsive for at least a half-hour in the newborn pig. We speculate that in view of these results, hypertensive peaks may play a role in the lack of autoregulation reported in stressed newborn infants.

In this study, we demonstrated a sparing effect on blood flow increases to specific regions (e.g. brain stem and cerebellar medulla) of the brain. Similar changes in regional brain blood flow have been described in adult cats $(1,10)$. Our group also has previously shown a sparing effect on blood flow reduction to the brain stem and cerebellum during hypotension in the newborn piglet (17). Thus, the vital centers of the brain (i.e. brain stem) are relatively well protected from perturbations in blood flow during fluctuations in blood pressure above or below the range of autoregulation.

The same pattern of selective blood flow increase to the cortex was also seen in the cerebellum in our study. Cerebellar hemorrhage is relatively frequent in preterm infants and often develops within the cerebellar cortex just below the pial capillary network which is poorly developed and in a continual process of remod- eling (25). The selective increase in blood flow to the cerebellar cortex found in our study suggests that hypertension may play a role in cerebellar hemorrhage. Similar to the findings by other investigators in adult cats (10), blood flow to the caudate nucleus did not increase during hypertension. The caudate nucleus forms the floor of the third ventricle representing the area where the germinal matrix exists in a more immature animal. However, the maturation of the pig brain at birth is similar to the human newborn at 36 wk of gestation (18); the germinal matrix has almost disappeared and the blood vessels supplying this area are greatly reduced compared to those seen earlier in gestation. One may speculate that hypertension may still increase blood flow to this area in a less immature animal.

Hypertension has been found by several investigators to cause vasoconstriction, reduced blood flow, and ischemic damage to the arterial boundary zones $(6,28)$ in the brain. The sites of periventricular leukomalacia, a common ischemic lesion of the newborn brain, are the boundary zones between centripetal and centrifugal arteries within the brain (25). We did not find any blood flow changes in the boundary zone during hypertension. The result of this study therefore seems to suggest that hypertension does not play an important role in the development of periventricular leukomalacia in the newborn.

The highly significant decrease in choroid plexus blood flow found in this study during hypertension has also been described in adult sheep treated with Aramine (24). Aramine is an adrenergic receptor stimulator and increases blood pressure mainly by peripheral vasoconstriction. The decrease in choroid plexus blood flow suggests a direct vasoconstrictive action of Aramine on the choroid plexus vessels and seems to confirm the previous finding (3) that the choroid plexus lacks a blood-brain barrier.

Pretreatment with atropine in group II successfully abolished the reflex bradycardia observed during the induction of hypertension in group I and resulted in a higher MABP (group II, Fig. 1). However, BBF did not increase in group II as in group I and vascular resistance remained elevated. Rudolph and Heymann (29) have shown that the newborn increases its cardiac output mainly by increasing heart rate. The heart rate increased after atropine pretreatment in group II and was significantly higher after induction of hypertension in this group than in group $I$. The pulse pressure was the same in both groups. Thus, although we did not measure cardiac output, the higher heart rate in group II and the similar pulse pressure in both groups make it unlikely that a decrease in cardiac output in group II as compared to group I could explain the failure of BBF to increase in group II.

The current theory to explain cerebral vasodilation in the presence of the arterial blood pressure exceeding the autoregulatory range is based upon the mechanical distending force of high pressure on the vessel wall (20). Sympathetic and parasympathetic nerves and receptors are abundantly present in the cerebrovascular bed $(7,8)$ and electrical stimulation of the cervical sympathetic chain has been shown to protect the brain against hypertensive insults $(1,10,11)$. Because the origin of 
cholinergic nerves in the brain is uncertain, electrical stimulation is not feasible. However, several authors have attempted to explore the influence of the parasympathetic nervous system on the cerebral circulation by administration of acetylcholine and the cholinergic muscarinic blocking agent, atropine. Atropine has been shown to abolish cerebral vasodilation within the autoregulatory range $(16,22)$. Using the cranial window method, Busija et al. (4) produced vasodilation of the pial arteries by topical application of acetylcholine. This dilation was blocked by intravenous injection of atropine. D'Alecy and Rose (5) also found cerebral vasodilation resulting in a large increase in cerebral blood flow after an intraarterial infusion of acetylcholine; blockade with atropine intravenously eliminated this vasodilation. Atropine has also been shown to enhance norepinephrine release from peripheral adrenergic nerve fibers in organs where terminal adrenergic and cholinergic axons run side by side (23) and may therefore increase the tone in the cerebral vasculature. We have shown that pretreatment with atropine eliminated the increase in BBF at blood pressure increases of $64 \%$ above baseline; these changes were associated with a sustained increase in CVR. This suggests that atropine may have extended the upper limb of the autoregulatory range either by directly blocking the cholinergic receptors and inhibiting cerebral vasodilation or indirectly by stimulating adrenergic release of norepinephrine and causing vasoconstriction.

In group II, the only change in BBF during hypertension was a decrease in choroid plexus blood flow similar to the decrease seen in group I (Fig. 2). This indicates that atropine has no influence on the direct vasoconstrictive effect of Aramine on the vessels of the choroid plexus.

In summary, hypertension induced pharmacologically with Aramine has the following effects on brain blood flow in the newborn piglet: 1) a sustained loss of autoregulation; 2) a sparing effect on the BBF increase to the brainstem; 3) a preferential increase in cerebellar cortical BBF suggesting an increased risk for hemorrhage in this area during hypertension; 4) no apparent effect on BBF to the boundary zone, suggesting that hypertension may not play an important role in the development of periventricular leukomalacia; and 5) a reduction in choroid plexus blood flow possibly because of a lack of a blood-brain barrier in this brain region. Atropine pretreatment before the induction of hypertension with Aramine results in a greater increase in MABP; however, atropine also prevents an increase in BBF during hypertension. Because relatively moderate hypertensive insults have been shown to be associated with significant increases in $\mathrm{BBF}$ in newborn piglets, hypertension may result in intraventricular hemorrhage in more immature species; the role of atropine in this context remains to be determined in future studies.

Acknowledgments. The authors wish to thank Ms. Carol Calista and Mr. Raymond Petit for their excellent technical assistance and Albert S. Most, M.D., F.A.C.C., and Mr. Tom DiVona of the Cardiovascular Research Laboratory of Rhode Island Hospital for their cooperation and assistance.

\section{REFERENCES}

1. Beausang-Linder M, Bill A 1981 Cerebral circulation in acute arterial hypertension-protective effects of sympathetic nervous activity. Acta Physiol Scand 111:193

2. Bejar R, Schneider H, Osorno L, Edwards D, Coen R, Gluck L 1981 Associa- tion of early aortograms and PDA ligation with intraventricular hemorrhage. Pediatr Res 15:650 (abstr)

3. Brightman MW, Reese TS 1969 Junction between intimately opposed cell membranes in the vertebrate brain. J Cell Biol 40:648

4. Busija DW, Heistad DD 1982 Atropine does not attenuate cerebral vasodilation during hypercapnia. Am J Physiol 242 (Heart Circ Physiol 11):H683

5. D'Alecy LG Rose CJ 1977 Parasympathetic cholinergic control of cerebral blood flow in dogs. Circ Res 41:324

6. Dinsdale HB, Robertson DM, Haas RA 1974 Cerebral blood flow in acute hypertension. Arch Neurol 31:80

7. Edvinsson L Neurolgenic mechanisms in the cerebrovascular bed. Acta Physiol Scand Suppl 427:1

8. Florence VM, Bevan JA 1979 Biochemical determinations of cholinergic innervation in cerebral arteries. Circ Res 45:212

9. Goddard J, Lewis RM, Armstrong DL, Zeller RS 1980 Moderate, rapidly induced hypertension as a cause of intraventricular hemorrhage in the newborn beagle model. J Pediatr 96:1056

10. Gross PM, Heistad DD, Strait MR, Marcus ML, Brody MJ 1979 Cerebral vascular responses to physiological stimulation of sympathetic pathways in cats. Circ Res $44: 288$

11. Heistad DD, Marcus ML 1979 Effect of sympathetic stimulation on the permeability of the blood-brain barrier to albumin during acute hypertension in cats. Circ Res 45:331

12. Hernandez MJ, Brennan RW, Bowman GS 1980 Autoregulation of cerebral blood flow in the newborn dog. Brain Res 184:199

13. Heymann MA, Payne BD, Hoffman JIE, Rudolph AM 1977 Blood flow measurements with radionuclide-labeled particles. Prog Cardiovasc Dis 20:55

14. Kontos HA, Wei EP, Dietrich WD, Navari RM, Povlishock JT, Ghatak N, Ellis EF, Patterson JL 1981 Mechanisms of cerebral arteriolar abnormalities after acute hypertension. Am J Physiol 240 (Heart Circ Physiol 9):H5I 1

15. Kontos HA, Wei EP. Navari RM, Levasseur JE, Rosenblum WI, Patterson JL 1978 Responses of cerebral arteries and arterioles to acute hypotension and hypertension. Am J Physiol 234 (Heart Circ Physiol 3):H371

16. Kuschinsky W, Wahl M, Neiss A 1974 Evidence for cholinergic dilatory receptors in pial arteries of cats. A microapplication study. Pfluegers Arch 347:199

17. Laptook AR, Stonestreet BS, Oh W 1982 Autoregulation of brain blood flow in the newborn piglet: regional differences in flow reduction during hypotension. Early Hum Dev 6:99

18. Laptook AR, Stonestreet BS, Oh W 1982 The effects of different rates of plasmanate infusions upon brain blood flow after asphyxia and hypotension in newborn piglets. J Pediatr 100:791

19. Lou HC, Lassen NA, Friis-Hansen B 1979 Impaired autoregulation of cerebral blood flow in the distressed newborn infant. J Pediatr 94:118

20. MacKenzie ET, Strandgaard S, Graham DI, Jones JV, Harper AM, Farrar JK 1976 Effects of acutely induced hypertension in cats on pial arteriolar caliber, local cerebral blood flow and the blood-brain barrier. Circ Res 39:33

21. Marshall TA, Marshall F II, Reddy PP 1982 Physiological changes associated with ligation of the ductus arteriosus in preterm infants. J Pediatr 101:749

22. Mchedlishvilli GI. Nikolaishvilli LS 1970 Evidence of a cholinergic nervous mechanism mediating the autoregulatory dilatation of the cerebral blood vessels. Pfluegers Arch 315:27

23. Muscholl E 1980 Peripheral muscarinic control of norepinephrine release in the cardiovascular system. Am J Physiol 239 (Heart Circ Physiol 8):H713

24. Page RB, Funsh DJ, Brennan RW, Hernandez MJ 1980 Choroid plexus blood flow in the sheep. Brain Res 197:532

25. Pape KE, Wigglesworth JS 1979 In: Haemorrhage, Ischaemia and the Perinatal Brain, No. 69/70, Clinics in Developmental Medicine. JB Lippincott Co, Philadelphia, pp 90 and 100

26. Purves MJ, James IM 1959 Observation on the control of cerebral blood flow in sheep fetus and newborn lamb. Circ Res 25:65

27. Reynolds ML, Evans CAN, Reynolds EOR, Saunders NR, Durbin GM, Wigglesworth JS 1979 Intracranial hemorrhage in the preterm sheep fetus. Early Hum Dev 3:163

28. Robertson DM, Dinsdale HB, Ayashi T, Tu J 1970 Cerebral lesions in adrenal regeneration hypertension. AM J Pathol 59:115

29. Rudolph AM, Heymann MA 1976 Cardiac output in the fetal lamb: the effects of spontaneous and induced changes of heart rate on right and left ventricular output. Am J Obstet Gynecol 124:183

30. Wallenstein S, Zucker CL, Fleiss JL 1980 Some statistical methods in circulation research. Circ Res 47:1

31. Wimberly PD, Lou HC, Pedersen H, Hejl M, Lassen NA, Friis-Hansen B 1982 Hypertensive peaks in the pathogenesis of intraventricular hemorrhage in the newborn: abolition by phenobarbitone sedation. Acta Pediatr Scand 71:537

32. Winer BJ 1971 In: Single Factor Experiments Having Repeated Measures on the Same Elements, No. 4, Statistical Principles in Experimental Design, 2nd ed. McGraw Hill, New York, p 26 